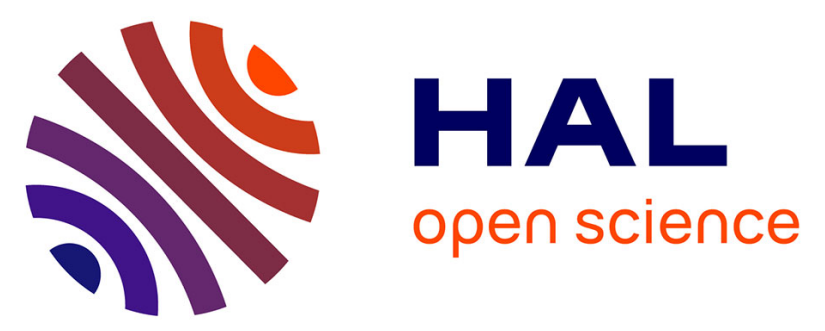

\title{
A double-digitising method for building 3D virtual trees with non-planar leaves: application to the morphology and light-capture properties of young beech trees (Fagus sylvatica)
}

Jean-Christophe J.-C. Chambelland, M. Dassot, A. Adam, N. Donès, Philippe Balandier, A. Marquier, M. Saudreau, G. Sonohat, Hervé Sinoquet

\section{To cite this version:}

Jean-Christophe J.-C. Chambelland, M. Dassot, A. Adam, N. Donès, Philippe Balandier, et al.. A double-digitising method for building 3D virtual trees with non-planar leaves: application to the morphology and light-capture properties of young beech trees (Fagus sylvatica). Functional Plant Biology, 2008, 35 (10), p. 1059 - p. 1069. 10.1071/FP08051 . hal-00454479

\author{
HAL Id: hal-00454479 \\ https://hal.science/hal-00454479
}

Submitted on 8 Feb 2010

HAL is a multi-disciplinary open access archive for the deposit and dissemination of scientific research documents, whether they are published or not. The documents may come from teaching and research institutions in France or abroad, or from public or private research centers.
L'archive ouverte pluridisciplinaire HAL, est destinée au dépôt et à la diffusion de documents scientifiques de niveau recherche, publiés ou non, émanant des établissements d'enseignement et de recherche français ou étrangers, des laboratoires publics ou privés. 
1

Functional plant biology, vol. 35, 2008, p. 1059-1069

2 Title: A double-digitizing method for building 3D virtual trees with non-planar leaves 3 4 5

6 Authors: Jean-Christophe Chambelland ${ }^{\mathrm{A}}$, Mathieu Dassot ${ }^{\mathrm{A}}$, Boris Adam ${ }^{\mathrm{A}}$, Nicolas Donès ${ }^{\mathrm{A}}$, 7 Philippe Balandier ${ }^{\mathrm{AB}}$, André Marquier ${ }^{\mathrm{A}}$, Marc Saudreau ${ }^{\mathrm{A}}$, Gabriela Sonohat $^{\mathrm{AC}}$, Hervé 8 Sinoquet $^{\mathrm{AD}}$

9

10

Addresses:

11

A UMR547 PIAF, INRA, UNIV BLAISE PASCAL, 234 Avenue du Brézet, F-63100

12

13

${ }^{\text {B }}$ Cemagref, UR EFNO, Domaine des Barres, F-45290 Nogent-sur-Vernisson, France

14

${ }^{\mathrm{C}}$ ENITAC, Site de Marmilhat, BP35, F-63370 LEMPDES, France

15

${ }^{\mathrm{D}}$ Corresponding author. Email: sinoquet@ clermont.inra.fr

16

17 Number of words: 6142 (Abstract to references)

18 Abstract: 185

19 Number of tables: 2

20 Number of figures: 10 


\section{Abstract}

We developed a double-digitizing method combining a hand-held electromagnetic digitizer and a non-contact three-dimensional (3D) laser scanner. The former was used to record the positions of all leaves in a tree and orientation angles of their lamina. The latter served to obtain the morphology of leaves sampled in the tree. As the scanner outputs a cloud of points, software was developed to reconstruct non-planar (NP) leaves composed of triangles, and to compute numerical shape parameters: midrib curvature, torsion and transversal curvature of the lamina. Combination of both methods allowed building 3D virtual trees with NP leaves.

The method was applied to young beech trees (Fagus sylvatica) selected in different sunlight environments (from 1 to $100 \%$ of incident light) in forest of central France. Leaf morphology responded to light availability, with more bent shape in well lit leaves. Light interception at the leaf scale by NP leaves was decreased from 4 to $10 \%$, for shaded and sunlit leaves compared to planar leaves. At the tree scale, light interception by trees made of NP leaves was decreased by 1 to $3 \%$ for $100 \%$ to $1 \%$ light, respectively.

Keywords: Virtual plants, laser scanner, electromagnetic digitizing 


\section{Introduction}

Most trees have a strong ability for structural modification in response to light availability. At the plant scale, leaf distribution has been reported to be more regular and more clumped in shaded and sunny environments, respectively (Planchais and Sinoquet 1998; Farque et al. 2001). Leaf attributes may also change, e.g. inclination and rolling angles of the whole lamina show significant changes with regard to irradiance level (Begg 1980; Niklas and Owens 1989; Heckathorn and DeLucia 1991; Midgley et al. 1992; Planchais and Sinoquet 1998). For example, in a recent study on Fagus sylvatica data showed that leaf number, mean leaf angle and leaf dry matter content per unit area increased with light availability (Balandier et al. 2007). In addition, several species may show structural changes affecting the leaf morphology, such as lamina folding or curling (Innes 1992; Muraoka et al. 1998; Fleck et al. 2003; Niinemets 2007). These multiple ways for changing the tree geometry has consequences for the plant's ability to intercept light, and usually allows plants to maximize light capture in low light and protect themselves against photo inhibition of photosynthesis in excess light (Pearcy et al. 2005).

Three-dimensional (3D) virtual tree modelling (Prusinkiewicz and Lindenmayer 1990; Weber and Penn 1995; Lintermann and Deussen 1998, Godin and Sinoquet 2005) has become a promising tool for quantifying structural responses in relation with both the geometry and the spatial distribution of the tree organs. In combination with radiation transfer models or foliage projection model, the quantification of light interception at tree scale has been widely addressed using virtual tree mock-ups constructed from measurements (e.g. Sinoquet and Rivet 1997, Sinoquet et al. 1998, Sonohat et al. 2006). Measurements are presently considered to be the most accurate approach to quantitatively represent the $3 \mathrm{D}$ tree architecture, because the actual features of tree geometry are taken into account. These processes are typically composed of two steps: an acquisition step consisting of capturing the 
geometrical features of the tree organs using a suitable digitizing device (e.g. Hanan and Room 2002), and a reconstruction step in which the resulting data are converted to a suitable 3D computer mock-up.

Hand-held electromagnetic digitizers (HHEMD) provide a robust way for quantifying the tree geometry in a systematic manner especially the capture of the spatial position and orientation of stems and leaves (Sinoquet and Rivet 1997; Sinoquet et al. 1998; Sonohat et al. 2006). However, HHEMD are tedious, time-consuming and often not enough precise for accurately capture the detailed leaf geometry, e.g. measuring the leaf edges (see Rakocevic et al. 2000 for white clover digitizing). This is the reason why most plant mock-ups constructed from HHEMD do not integrate the non-planar (NP) leaf structure. Indeed leaf shape is often reduced to planar polygons, de facto neglecting a potential influence of leaf curvature or leaf torsion on the whole-plant light interception.

Conversely, other emerging 3D capture devices such as non-contact laser scan digitizers (NCLSD) have been used for various plant measurement and reconstruction (e.g. Tanaka et al. 1998; Kaminuma 2004; Rice et al. 2005; Dornbusch et al. 2007). Indeed, NCLSD are able to rapidly quantify the surface of an object under investigation as a dense set of points and consequently they seem potentially useful for modelling $3 \mathrm{D}$ virtual trees at a fine scale. A drawback of this type of device is that organs that are overlaid are not "viewed" by the scanner, e.g. a twig under a leaf, and thus not considered. Other drawback is the segmentation task which is needed to clearly distinguish subsets of points related to the plant organs such as leaves and stems. In practice automatic segmentation remains an open problem due to holes, spikes, hidden parts, and data points that do not belong to the scanned tree (Hanan et al. 2004). Therefore the segmentation task must in most cases be manually achieved (Dornbusch et al. 2007) through numerous fastidious interactive manipulations. 
The present work was an attempt to combine the advantages of HHEMD and NCLSD for building 3D virtual trees composed by NP leaves. In this goal, a four-step reconstruction protocol was investigated: i) a 3Space Fastrack Polhemus HHEMD ( $\underline{\text { www.polhemus.com }) ~}$ was used to describe the location and orientation of all leaves in the tree, and the maximum width and length of each leaf was manually measured with a ruler; ii) a Konica VIVID 910

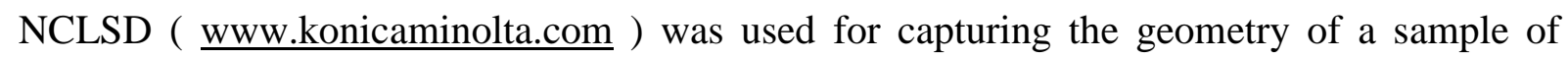
leaves leading for each digitized leaf to a dense set of 3D points; iii) each set of leaf points was processed to extract numerical parameters featuring the leaf 3D morphology, and derive a normalized triangulated leaf model by fitting a set of triangles onto the 3D leaf data points; iv) the HHEMD data were combined with the triangulated leaves in order to get 3D tree mockups with NP leaves. This framework was applied on young European beech trees (Fagus sylvatica) selected in different sunlight environments in forest in central France, in order to investigate how morphological leaf parameters change with light availability and the consequences on light capture ability.

\section{Material and methods}

\section{Tree selection in a light gradient}

Eleven young beech trees were selected in the Chaîne des Puys, a mid-elevation volcanic mountain range situated in the Auvergne region of France $\left(45^{\circ} 42^{\prime} \mathrm{N}, 2^{\circ} 58^{\prime} \mathrm{E}\right)$. All trees except one were located in a forest dominated by Pinus sylvestris. Light availability for each sapling was estimated as follows. A digital fisheye camera fixed in a self-levelling device was positioned just above the sapling, with the camera objective perpendicular to the soil surface. The camera was connected to a PC for real-time photograph segmentation into sky and vegetation pixels, and for analysis of light availability in percent of above canopy value (\%light) with software PiafPhotem (Adam et al. 2006). The trees were chosen in the range of 
$111 \%$ light between 1 and $100 \%$, i.e. from the limit of beech growth in the very shade to open

112 area. Trees were separated in four light classes (Table 1). Beech height ranged between 0.4 113 and $1.1 \mathrm{~m}$, and included between 110 and 3400 leaves.

116 We only considered leaves in this study. While petioles and branches participate to the

117 modification of canopy architecture and thus, indirectly, to light interception, leaf distribution

118 in space takes into account these features and the time for digitizing the tree (see below) is

119 accordingly reduced. A four-step 3D tree mock-up reconstruction method was developed.

120 First, the HHEMD was used to measure all leaf positions and orientation angles of each tree,

121 and the maximum width and length of each leaf was manually measured with ruler. This step

122 was realised in a non-destructive manner, by digitalizing and measuring the trees directly in

123 their natural environment. Second, 3D laser scans of nine individual leaves per tree (three

124 leaves in each of the lower, middle and upper part of the tree) were produced with the

125 NCLSD. The scans were realised on freshly harvested leaves which were transported (in

126 about one hour of travel) in plastic bag from the Chaîne des Puys to a scanning lab. Third,

127 each set of 3D scanner leaf points was computer processed to extract leaf shape parameters

128 and to produce a normalized triangulated leaf model. Fourth, the triangulated leaf models

129 were positioned in the tree structure according to leaf positions, orientations and dimensions 130 measured in step one.

133 A 3Space Fastrack Polhemus HHEMD ( www.polhemus.com ) was used to digitize all leaves

134 in each selected tree. This device is composed of a transmitter and a receiver connected to a 
135 central unit. Both the transmitter and receiver contain a triad of electromagnetic coils. Those

136 in the transmitter are supplied with alternating voltage, so that they emit alternating magnetic

137 fields. When located in the magnetic fields, coils in the receiver show induced currents, the

138 value of them is related to the location and orientation of the receiver with regard to the

139 transmitter (Polhemus Inc. 1993). In practice, the transmitter must be placed near the target

140 tree for defining a global 3D Cartesian reference system $(\mathbf{O}, \mathbf{X}, \mathbf{Y}, \mathbf{Z})$. The receiver is inlayed

141 into a handle which allows an operator collecting/picking 3D points on the plant. The

142 accuracy of the device allows an approximate capture resolution of $0.8 \mathrm{~mm}$ in a volume

143 depending on the magnetic source, here up to $3 \mathrm{~m}$ around the transmitter but acquisition is

144 possible up to $9 \mathrm{~m}$ with a more powerful transmitter. Each measurement produces 6 data,

145 namely a triplet of Cartesian coordinates locating the digitized point in the global reference

146 system, and the receiver orientation provided as Euler angle triplet i.e. azimuth, elevation and

147 roll angles. Data acquisition is driven by software PiafDigit (Donès et al. 2006) available at

148 http://www2.clermont.inra.fr/piaf/eng/download/download.php .

149 For leaf digitizing, the receiver was pointed at the proximal point of the lamina (i.e. the

150 junction between petiole and lamina) and oriented parallel to the midrib and to the mean plane

151 of the lamina (Fig. 1a). The receiver inclination was visually approximated by the leaf axis,

152 i.e. the line between the proximal and distal points of the midrib. With this orientation, the

153 Euler angles were the midrib azimuth, the midrib inclination and the roll angle of lamina

154 around the midrib (Sinoquet et al. 1998). During digitizing, leaf length and maximum leaf

155 width along the midrib were manually measured with a ruler, and the data were input in the

156 same software PiafDigit. The output of the HHEMD measurements was an ASCII file per

157 tree. Each file contained the list of tree leaves with their maximum width and length,

158 orientation angles and spatial coordinates. The related tree mock-ups with planar leaves were 
visualized with the software

VegeSTAR

also

available

at

160 http://www2.clermont.inra.fr/piaf/eng/download/download.php (Adam et al. 2002) (Fig. 2a).

NCLSD for capturing the leaf geometry (second step)

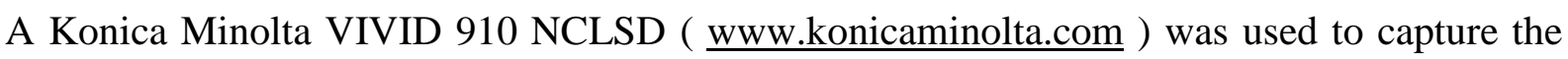
leaf geometry. This device is composed of a single parallelepiped unit presenting two circular apertures hosting a laser emitting unit and a charge-coupled device (CCD) camera, respectively (Fig. 1b).

167 The VIVID 910 uses a light-stripe method to acquire object geometry. This technique (Fig. 3) consists of emitting a horizontal red laser ray through a cylindrical lens to the object and to convert the reflected light into distance information by using an active triangulation principle.

The conversion is achieved through the CCD (here a $640 * 480$ pixels) camera. The process is

171 repeated by scanning the light stripe vertically on the object surface using a rotating mirror.

172 The result is a dense set of 3D points outlining the part of the object which is visible for the

173 CCD. The VIVID 910 is provided with three interchangeable receiving lenses allowing an

174 angular field of view approximately covering $10 \mathrm{~cm}^{2}$ to $1 \mathrm{~m}^{2}$. The recommended scan distance

175 is between $0.6 \mathrm{~m}$ and $2.5 \mathrm{~m}$ and the scanner resolution, i.e. the distance between two digitized

176 points, varies from $0.039 \mathrm{~mm}$ to $0.090 \mathrm{~mm}$ according to the lens. An efficient embedded auto

177 focus technology allows automatically detection of the optimal scan distance for a given lens

178 and a given object. The number of digitized points varies with two resolution modes and the

179 ratio between the object size and the CCD field of view. In addition, a 24-bit colour image is

180 captured at the same time by the CCD camera. For our study, the VIVID 910 was driven from

181 the commercial software rapidform2006 (INUS Technology, Seoul, Korea). This industrial

182 software is widely used for computer-aided design issues, and provides a comprehensive suite 
183 of tools designed to process real-world data, from 3D scanning devices control to parametric

184 surface reconstruction.

185 The smallest lens with the fine resolution mode $(0.039 \mathrm{~mm})$ was used for capturing the 186 geometry of 99 leaves, i.e. 9 leaves per beech tree. Three leaves were harvested in each of the 187 lower, middle and upper part of the tree. Each of the 99 leaves was positioned in front of the 188 VIVID so that the CCD camera viewed maximum projected area of the leaf (Fig. 1b). The

189 VIVID was levelled and the leaf axis was set vertically, i.e. parallel to the VIVID Y-axis.

190 Identification of the leaf axis in both the HHEMD and NCLSD data ensured the geometric 191 consistency between 3D data at tree and leaf scales. During our measurements, we overcame 192 segmentation problem related to the use of NCLSD since all digitised points belonged to the 193 scanned leaf. Each 3D digitized leaf included between 10,000 and 30,000 points depending on 194 leaf size. An image of the 3D data points for a digitized medium-sized leaf is given in Fig. 4a.

195 Leaf shape parameter extraction and leaf triangulation in 3D (third step)

196 Three-dimensional data obtained from the NCLSD for each leaf were processed for both 197 extracting a set of numerical parameters featuring the leaf morphology and for constructing a 198 non-planar triangulated model of each harvested leaf. An application programming interface 199 which allows direct access to data structures and algorithms in rapidform2006 via the 200 Microsoft Visual C++ programming language was used to develop a rapidform2006 plug-in. 201 Extracted morphological parameters were midrib length $\mathrm{L}(\mathrm{mm})$, maximum leaf width W 202 (mm), leaf area A $\left(\mathrm{mm}^{2}\right)$, midrib curvature $\mathrm{C}\left(\mathrm{mm}^{-1}\right)$, openness angle between two half203 laminas $\mathrm{O}\left({ }^{\circ}\right)$, lamina twirl $\mathrm{T}\left({ }^{\circ}\right)$, transversal curvature angle of lamina $\mathrm{TC}\left({ }^{\circ}\right)$ and symmetry 204 between the two half-laminas S, i.e. the ratio of the left leaf half width to the total leaf width 205 along its midrib. The extraction algorithm was based on a set of slicing free form NURBS 206 curves (Piegl and Tiller 1997) equidistantly subdividing the leaf along its midrib (Fig. 4b). 207 The set of 3D points for each leaf was transformed into an oriented set of curves: one curve 
208 for modelling the midrib, and n curves for modelling the transversal shape of the lamina (Fig.

209 4b). The shape parameters were then extracted from the length and the curvature of the $(n+1)$

210 curves. The mean, minimal and maximal values of the shape parameters were computed for

211 each leaf from the values of the $(n+1)$ curves. Additional parameters were computed from A,

$212 \mathrm{~L}$ and $\mathrm{W}$, namely the ratio $\mathrm{W} / \mathrm{L}$, and the allometric coefficient $\mathrm{K}$ defined as the ration between

213 A and the product L W. One can notice the difference between the quantification of the

214 midrib curvature, expressed in $\mathrm{mm}^{-1}$, and the quantification of the transversal curvatures,

215 expressed in degrees $\left(^{\circ}\right)$. The former is the mathematical differential curvature of the midrib

216 curve, i.e the inverse of the radius of the osculating circle (Piegl and Tiller 1997; Fig. 5). This

217 curvature has been proved efficient for quantifying the oscillations of the midrib because of

218 its low number of curvature variations. Conversely, practical evidences showed us that the

219 differential curvature was not a good solution for measuring the curvature of the transversal

220 NURBS curves because of their high number of local variations, often leading to null or

221 enormous curvature. For this reason, we preferred to measure the transversal curvature of the

222 leaf using an angle, which can be interpreted as the aperture angle of the half laminas (Fig. 5).

223 The quantity $\mathrm{S}$ is a ratio of two lengths which represents the level of symmetry of the leaf

224 along its midrib. This ratio is computed for each slicing curve. It is defined as the ratio

225 between the left half-lamina width (i.e. the length of the slicing curve from le left bound of

226 the leaf until the intersection with the midrib) and the total width of the leaf (i.e. the total

227 length of the slicing curve). S varies from 0.0 for a very dissymmetric piece of leaf until 0.5

228 for a perfectly symmetric peace of leaf. Note that the "left" direction is defined by the

229 direction of the negative abscissa (X-) of the coordinate system linked to the laser scanner

230 (Fig 5). 
232 A triangulated model of each leaf composed of $8 \mathrm{n}$ triangles was also constructed from the $233(\mathrm{n}+1)$ curves (Fig. 4c). The triangulated leaves were normalized so that the distance between 234 the proximal and distal point of the lamina in the leaf model was 1 . Here n was set to 9, 235 leading to 72 triangles per leaf. This value is a compromise between accuracy in the NP leaf 236 description and file size. Morphological parameters were exported to Microsoft Excel files 237 while the triangulated leaves were converted in VegeSTAR format as a set of triangles for 238 further visualization and light interception computation. We verified that the leaf surface 239 covered by the digitized points was equivalent to the one given by the triangulated leaf model 240 in VegeSTAR $\left(\mathrm{R}^{2}=0.98\right.$ with a $2 \%$ error between values given by the digitized and the 241 triangulated leaves).

243 Replacing the planar hexagonal leaves by non-planar triangulated leaves (fourth 244 step)

245 A specific computer program was developed for replacing the planar hexagonal leaves by the 246 NP triangulated leaves in the eleven tree mock-ups built from the HHEMD. For each planar 247 leaf in the tree, a normalized triangulated leaf model was randomly selected among those 248 owning to the same layer (upper, medium or lower) in the same tree. In order to support the 249 comparison of planar leaves with NP leaves, the selected normalized triangulated leaf model 250 was then scaled, rotated and translated in the tree structure according to the geometrical 251 attributes of the planar leaf i.e. $\mathrm{L}^{2}$, Euler angle triplet and Cartesian coordinates respectively. 252 The geometry of the 3D trees with NP leaves were saved as VegeSTAR files as a collection 253 of triangles for further visualization (Fig. 2b) and light interception computations. 
Three-dimensional mock-ups of both, individual leaves and trees were used in software

257 VegeSTAR for light interception computations (Adam et al. 2002). In the software, the 3D 258 scene elements are geometrical primitives assigned with false colours. The principle of 259 VegeSTAR consists of taking a picture of the 3D scene from the sun (or any other light 260 source) direction $\Omega$ with a virtual orthographic camera (Sinoquet et al. 1998). The scene 261 elements seen on the picture are those lit from the view direction. The amount of projected 262 area intercepting light in direction $\Omega$ is then estimated from the coloured pixel counts in the 263 image. Light interception is finally characterized by the variable STAR (Silhouette to Total Area Ratio; Carter and Smith 1985; Oker-blom and Smolander 1988), which is the ratio between the projected area seen on the image and the total area contained in the scene. As

STAR depends on the incident direction $\Omega$, the sky hemisphere was divided in 46 solid angle 267 sectors of equal measure, according to the Turtle sky proposed by Den Dulk (1989). 268 Directional STAR values were computed for the central direction of each solid angle sector. 269 Directional STAR values then were summed up over the sky hemisphere after weighting with 270 coefficients derived from the Standard OverCast distribution of sky radiance (Moon and 271 Spencer 1942). The resulting value $\mathrm{STAR}_{\mathrm{SKY}}$ characterized light interception over the sky 272 vault. Both directional and hemispherical STAR values were computed at the individual leaf 273 scale for the 99 laser-scanned leaves displayed with horizontal leaf axis and null whole lamina 274 rolling. STAR values were also computed at the tree scale with planar leaves and NP leaves, 275 i.e. taking into account the size, orientation and location of each leaf in the tree. The use of the 276 STAR at tree level as an indicator of light interception efficiency was previously validated for 277 beech (Balandier et al. 2007); diameter growth (or biomass increment) of young beeches was 278 related to the combination of STAR, leaf area, and available light above the young beeches 279 with a good accuracy $\left(\mathrm{r}^{2}=0.86 ; \mathrm{p}<0.0001\right)$. 
281

282

283

284

285

\section{Statistical data analysis}

The analysis of variance of leaf parameters (table 2) was determined using a mixed general linear model, with the mixed procedure (Proc Mixed) in SAS version 8.2 (Christophe et al. 2006). The effects of individual plants were added as random effects in the error of the model, using the repeated option in Proc Mixed. The variance-covariance matrix of the error was specified by an autoregressive model. When data were analysed by regression (figures 7 to 10) differences in the slopes between different light classes were tested with an F test after linearization if necessary.

\section{Results}

\section{Leaf morphology}

The leaf morphology depended on the light available above the plant. Shaded plants were almost flat becoming more bent when exposed to increased light above the plant (Fig. 6). A quantitative analysis of the leaf morphology parameters showed a significant effect of \%light on the following parameters (Table 2): minimal openness angle between the two half-laminas $\left(\mathrm{O}_{\text {min }}\right)$, maximal lamina twirl angle around the midrib $\left(\mathrm{T}_{\max }\right)$, minimal transversal curvature angle $\left(\mathrm{TC}_{\mathrm{min}}\right)$, and allometric coefficient $\mathrm{K}$. Midrib curvature $\mathrm{C}$ did not show any significant change with \%light, although it would contribute to strengthen the bent aspect of leaves. The higher value of $\mathrm{K}$ in full light meant that the same leaf area was achieved with smaller leaf length and leaf width (no significant change was found in the ratio W/L).

\section{Light interception at leaf scale}

A linear regression analysis between individual leaf area and its projection averaged over all sky directions showed differences in light capture efficiency according to \%light (Fig. 7; 
slopes were statistically different at $\mathrm{P}<0.0001)$. Higher light led to lower $\mathrm{STAR}_{\mathrm{SKY}}$, with

306 slope values of $0.96-0.97,0.94$ and 0.90 for plant irradiance between $1-15 \%, 30-40 \%$ and

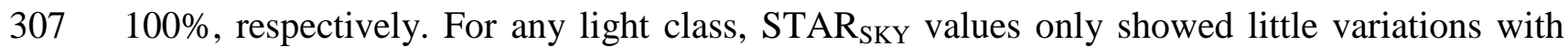

308 leaf size, since the coefficient $\mathrm{R}^{2}$ was always very high.

309 Directional STAR values showed high variation with the elevation angle $\mathrm{h}$ of the incident 310 beam direction (Fig. 8). The main source of variation was the angle between the beam 311 direction and the leaf normal, as directional STAR of a horizontal planar leaf is defined by the 312 sine function $\sin (\mathrm{h})$, i.e. STAR ranging from 0 to 1 for $\mathrm{h}$ between 0 and $90^{\circ}$. However, 313 directional STAR values of NP leaves showed some deviations with regard to that of a planar 314 leaf. For low elevation angles $\left(\mathrm{h}<20^{\circ}\right)$, STAR values of NP leaves was slightly higher than 315 that of planar leaves, while STAR of NP leaves was lesser than that of planar leaves for $316 \mathrm{~h}>20^{\circ}$. The magnitude of the deviation for both low and high elevation angles was related to $317 \%$ light, with greater deviations for more lighted plants (Fig. 8; $\mathrm{P}=0.009$ ).

\section{Light interception at tree scale}

320 STAR $_{\text {SKY }}$ values of the whole trees with NP leaves were also lower than those of trees with 321 planar leaves (Fig. 9; slope of the regression line statistically different from the 1:1 line at $\mathrm{P}<$ 322 0.0001). In contrast with the leaf scale, the tree STAR $_{\mathrm{SKY}}$ decrease when tree was built with 323 NP leaves did not depend on \%light, and the magnitude of STAR reduction was a maximum of $3.2 \%$ for all light classes. Moreover the higher \%light, the lower STAR value, leading to a smaller effect of NP leaves on the absolute STAR $_{\text {SKY value at tree scale. }}$

326 For \%light below 40\%, tree directional STAR increased with elevation angle (Fig. 10). For 327 low elevation angles, trees with \%light below 40\% showed similar values of directional 328 STAR around 0.21 without any differences between trees with planar leaves and trees with 
329 NP leaves. For elevation angles above $20^{\circ}$, differences in directional STAR between \%light 330 classes increased with elevation angles (slopes of the regression line after linearization 331 statistically different between \%light classes at $\mathrm{P}<0.0001$ ), with higher STAR values for the 332 more shaded plants (Fig. 10). For that elevation angles higher than $20^{\circ}$ STAR of trees with 333 NP leaves was always slightly lower than that of trees with planar leaves, with the maximum 334 differences being around $45-50^{\circ}$ of elevation. The tree in full light showed a particular 335 behaviour with a small bell shaped curve of directional STAR with elevation and only a very 336 slight decrease in case of trees with NP leaves. 


\section{Discussion}

338 A double-digitizing method for 3D plant structure

339 We developed a double-digitizing method to build 3D plants with non-planar leaves (NP

340 leaves). Indeed only one digitizing method would be insufficient for this purpose. Contact

341 digitizers (e.g. hand-held electromagnetic digitizer, HHEMD, used here) are not accurate

342 enough and only allow a rough description of the 3D leaf shape (e.g. Rakocevic et al. 2000).

343 Non-contact laser scan digitizers (NCLSD) are better suited for continuous surfaces (i.e. their

344 current use in industrial applications) than for plants where many small surfaces are

345 distributed in the vegetation volume. This is the reason why laser scanner applications to

346 building 3D plants deal with simple isolated plants with a few organs (Kaminuma et al. 2004;

347 barley, Dornbush et al. 2007) or isolated leaves (Loch 2004). The scan of a leaf is easy and

348 very rapid (less than 1 minute) in the lab where focus is easy to do with controlled light

349 conditions. The scan could be more complicated with in situ organs in the field conditions

350 with organs moved by the wind and none controlled light conditions leading to many artefacts

351 in the point cloud. Scanning in the field would obviously require plant protection, at least

352 from wind and light.

353 Scanner application to more complex whole plants is presently limited by the segmentation of

354 the 3D data set, as suitable automatic algorithms are for the moment unavailable. Moreover

355 scanner beams only hit the plant organs making the plant hull, preventing one to get

356 information inside the plant volume. This problem is emphasized in plants with high foliage

357 density. Dutilleul et al. (2008) used a computed-tomography (CT) scanner to get a full

358 description of the whole plant as a set of 3D data points, i.e. solving the masking effect. This

359 is a great improvement but this is limited to small plants (i.e. able to be inserted within the CT 
scanner). Moreover algorithms for the segmentation of the 3D data points, i.e. point

361 assignation to plant organs, are also unavailable.

362 In consequence, the combination of HHEMD and NCLSD with suitable software turns out to

363 be a reliable approach for rapidly acquiring detailed plant architecture data. A constant

364 problem with such approaches is the validation of the built mock-up, and particularly of the

365 light intercepting surface, i.e. leaf area. What could be a method of reference to measure leaf

366 area, particularly for NP leaves? A flat-bed scanner is probably no more accurate that the

367 scanner laser and in case of discrepancy between both measurements it would be difficult to

368 say which is the "true" leaf area. The same problem is true at the tree scale. It was already

369 assessed by example by Drouet (2003) who compared direct measurements of maize

370 architecture with a 3D-digitization technique. The conclusion was that both techniques were

371 effective; the question is more linked to which resolution we want the spatial data.

Effect of light availability on the leaf morphology and consequences on light capture ability

375 Non-planar leaf morphology is significantly dependent on light availability, with flatter leaves

376 in shaded environment. This is in agreement with the only study we found on this topic for

377 broad-leaves species (Fleck et al. 2003). In this previous study, the 3D leaf shape was

378 characterised by the average cross-sectional angle between the leaf halves, which was derived

379 from manual measurements. This angle is similar to the openness angle $\mathrm{O}$ used in the present

380 study. For beech leaves, Fleck et al. (2003) found a larger range in openness angles, i.e. $170^{\circ}$

381 to $90-100^{\circ}$ for shaded and full lit leaves, respectively. Of course, using the laser scanner

382 method allowed us a more detailed characterization of the 3D leaf shape, showing that several

383 parameters accounting for the 3D shape also responded to light availability (Table 2). 
384 Light capture at both leaf and tree scales decreased when the 3D shape of leaves was

385 emphasised, i.e. for higher light availability. This is in agreement with the few previous 386 reported results. At the leaf scale, Fleck et al. (2003) showed lower interception for smaller 387 openness angles between leaf halves, and the decrease in light interception was higher for 388 direct than for diffuse radiation. Our results cannot be directly compared to those of Fleck et 389 al. (2003), because they dealt with direct and diffuse radiation at the daily scale. Rather we 390 showed that differences between planar leaves and NP leaves in directional light interception 391 is low for low elevation angles and markedly increases for higher elevation angles.

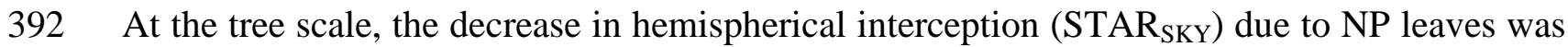
393 a maximum of $3 \%$ mainly for the most shaded beeches (Fig. $9 \& 10$ ). The absence of strong 394 differences between light levels might be related to compensation from other structural 395 changes, and among other a higher leaf area density observed in sunny beech plants (e.g. 396 Planchais and Sinoquet 1998; Delagrange et al. 2005). A 3\% decrease of light interception at 397 the tree scale may seem relatively low, but this is similar to the effect of other plant processes 398 on carbon acquisition, e.g. the spatial distribution of leaf nitrogen in tree canopies (Hollinger 399 1996) and heliotropism in cotton crops (Ehleringer and Hammond 1987). The competitive 400 advantage of such a decrease in light interception could be that NP leaves allow better 401 irradiance distribution over the tree leaf area and light penetration into deeper canopy leaves, 402 with positive consequences on the carbon gain by the plant (Niinemets 2007).

\section{Acknowledgements}

405 This project was funded by INRA, program ECOGER 'Bases écophysiologiques d'une 406 gestion durable des forêts hétérogènes' and project PREVOIR funded by the Conseil Régional 407 d'Auvergne. 


\section{References}

409 Adam B, Benoît JC, Balandier P, Marquier A, Sinoquet H (2006) 'PiafPhotem - software to 410 threshold hemispherical photographs. Version 1.0.' (UMR PIAF INRA-UBP: Clermont411 Ferrand, France and ALLIANCE VISION: Montélimar, France)

412 Adam B, Donès N, Sinoquet H (2002) 'VegeSTAR - software to compute light interception 413 and canopy photosynthesis from images of 3D digitised plants. Version 3.0.' (UMR PIAF 414 INRA-UBP: Clermont-Ferrand)

415 Balandier P, Sinoquet H, Frak E, Giuliani R, Vandame M, Deschamps S, Coll L, Adam B, 416 Prévosto B, Curt T (2007) Six-year evolution of light use efficiency, carbon gain and growth 417 of beech saplings (Fagus sylvatica L.) planted under Scots pine (Pinus sylvestris L.) 418 shelterwood. Tree Physiology 27, 8, 1073-1082.

419 Begg JE (1980) Morphological adaptations of leaves to water stress. In 'Adaptation of Plants 420 to Water and High Temperature Stress'. (Eds NC Turner, PJ Kramer) pp. 33-42. (John Wiley: $421 \quad$ New York)

422 Carter GA, Smith WK (1985) Influence of shoot structure on light interception and 423 photosynthesis in conifers. Plant Physiology 79, 1038-1043.

424 Christophe A, Moulia B, Varlet-Grancher C (2006) Quantitative contributions of blue light 425 and PAR to the photocontrol of plant morphogenesis in Trifolium repens (L.). Journal of 426 Experimental Botany 57, 2379-2390.

427 Delagrange S, Montpied P, Dreyer E, Messier C, Sinoquet H (2006) Does shade improve light 428 interception efficiency? A comparison among seedlings from shade tolerant and intolerant 429 temperate deciduous tree species. New Phytologist 172, 293-304.

430 Den Dulk JA (1989) 'The interpretation of remote sensing, a feasibility study' PhD Thesis 431 (Wageningen University: Wageningen, The Netherlands) 
432 Donès N, Adam B, Sinoquet H (2006) 'PiafDigit - software to drive a Polhemus Fastrak 3

433 SPACE 3D digitiser and for the acquisition of plant architecture. Version 1.0.' (UMR PIAF

434 INRA-UBP: Clermont-Ferrand)

435 Dornbusch T, Wernecke P, Diepenbrock W (2007) A method to extract morphological traits 436 of plant organs from 3D point clouds as a database for an architectural plant model. 437 Ecological Modelling 200, 119-129.

438 Drouet JL (2003) MODICA and MODANCA: modelling the three-dimensional shoot 439 structure of graminaceous crops from two methods of plant description. Field Crops Research $440 \quad 83,215-222$.

441 Dutilleul P, Han L, Smith DL (2008) Plant light interception can be explained via computed 442 tomography scanning - Demonstration with pyramidal cedar (Thuja occidentalis, Fastigiata). 443 Annals of Botany 101, 19-23.

444 Ehleringer JR, Hammond SD (1987) Solar tracking and photosynthesis in cotton leaves. 445 Agricultural and Forest Meteorology 39, 25-35.

446 Farque L, Sinoquet H, Colin F (2001) Canopy structure and light interception in Quercus 447 petraea (Matt.) Liebl. seedlings in relation to light regime and plant density. Tree Physiology $448 \quad 21,1257-1267$.

449 Fleck S, Niinemets U, Cescatti A, Tenhunen J (2003) Three-dimensional lamina architecture 450 alters light-harvesting efficiency in Fagus: a leaf-scale analysis. Tree Physiology 23, 577-589.

451 Godin C (2000) Representing and encoding plant architecture: a review. Annals of Forest 452 Science 57, 413-438.

453 Godin C, Sinoquet H, (2005) Functional-structural plant modelling. New Phytologist 166, $454 \quad 705-708$. 
455 Hanan JS, Loch B, McAleer T (2004) Processing laser scanner data to extract structural 456 information. In: 'Proceedings of the 4th International Workshop on Functional-Structural 457 Plant Models'. (Eds C Godin et al.) pp. 9-12. (CIRAD: Montpellier)

458 Hanan J, Room P (2002) 'Floradig User Manual.' (Centre for Plant Architecture Informatics, 459 University of Queensland: Brisbane, Australia)

460 Heckathorn SA, DeLucia EH (1991) Effect of leaf rolling on gas exchange and leaf 461 temperature of Andropogon gerardii and Spartina pectinata. Botanical Gazette 152, 263-268.

462 Hollinger DY (1996) Optimality and nitrogen allocation in a tree canopy. Tree Physiology 16, $463 \quad 627-634$.

464 Innes JL (1992) Observations on the condition of beech Fagus sylvatica L. in Britain in 1990. 465 Forestry 65, 35-60.

466 Kaminuma E, Heida N, Tsumoto Y, Yamamoto N, Goto N et al. (2004) Automatic 467 quantification of morphological traits via three-dimensional measurement of Arabidopsis. The 468 Plant Journal 38, 358-365.

469 Lintermann B, Deussen O (1998) A modelling method and user interface for creating plants. 470 Computer Graphics Forum 17, 73-82.

471 Loch (2004) 'Surface fitting for the modelling of plant leaves.' PhD thesis (University of 472 Queensland: Brisbane, Australia)

473 Midgley GF, Rutherford MC, Davis GW, Bösenberg J de W (1992) Photosynthetic responses 474 of heliophilus Rhus species to environmental modification by invasive shrubs. Functional 475 Ecology 6, 334-345.

476 Moon P, Spencer DE (1942) Illumination from a non-uniform sky. Transactions of the 477 Illumination Engineering Society 37; 707-726. 
478 Muraoka H, Takenaka A, Tang Y, Koizumi H, Washitani I (1998) Flexible leaf orientations

479 of Arisaema heterophyllum maximize light capture in a forest understorey and avoid excess 480 irradiance at a deforested site. Annals of Botany 82, 297-307.

481 Niinemets U (2007) Photosynthesis and resource distribution through plant canopies. Plant, 482 Cell and Environment 30, 1052-1071.

483 Niklas KJ, Owens TG (1989) Physiological and morphological modifications of Plantago 484 major (Plantaginaceae) in response to light conditions. American Journal of Botany 76, 370485382.

486 Oker-Blom P, Smolander H (1988) The ratio of shoot silhouette area to total needle area in 487 Scots pine. Forest Science 34, 894-906.

488 Pearcy RW, Muraoka H, Valladares F (2005) Crown architecture in sun and shade 489 environments: assessing function and trade-offs with a three-dimensional simulation model. $490 \quad$ New Phytologist 166, 791-800.

491 Piegl L, Tiller W (1997) 'The NURBS book, 2nd ed.' (Springer: New-York)

492 Planchais I, Sinoquet H (1998) Foliage determinants of light interception in sunny and shaded 493 branches of Fagus sylvatica. L. Agricultural and Forest Meteorology 89, 241-253.

494 Polhemus Inc. (1993) '3SPACE FASTRAK User's Manual, Revision F.' (Polhemus Inc.: 495 Colchester, VT)

496 Prusinkiewicz P, Lindenmayer A (1990) 'The Algorithmic Beauty of Plants.' (Springer497 Verlag: New York)

498 Rakocevic M, Sinoquet H, Christophe A, Varlet-Grancher C (2000) Assessing the geometric 499 structure of a white clover (Trifolium repens) canopy using 3-D digitising. Annals of Botany $500 \quad 86,519-526$. 
501 Rice SK, Gutman C, Krouglicof N (2005) Laser scanning reveals bryophyte canopy structure.

502 New Physiologist 166, 695-704.

503 Sinoquet H, Rivet P (1997) Measurement and visualisation of the architecture of an adult tree

504 based on a three-dimensional digitising device. Trees: Structure and Function 11, 265-270.

505 Sinoquet H, Thanisawanyangkura S, Mabrouk H, Kasemsap P (1998) Characterization of the

506 light environment in canopies using 3D digitising and image processing. Annals of Botany 82,

$507 \quad 203-212$.

508 Sonohat G, Sinoquet H, Kulandaivelu V, Combes D, Lescourret F (2006) Three-dimensional

509 reconstruction of partially 3D digitised peach tree canopies. Tree Physiology 26, 337-351.

510 Tanaka T, Yamaguchi J, Takeda Y (1998) Measurement of forest canopy structure with a

511 laser plane range-finding method - development of a measurement system and applications to

512 real forests. Agricultural and Forest Meteorology 91, 149-160.

513 Weber J, Penn J, (1995) Creation and rendering of realistic trees. SIGGRAPH 95 514 proceedings, pp. 119-128. 


\section{Tables}

516 Table 1. Distribution of eleven selected young Fagus sylvatica trees in four light classes in

517 forest stands of central France.

\begin{tabular}{|c|c|c|}
\hline Light class & Class bounds (\%light) & Number of trees \\
\hline 1 & $1-5 \%$ & 4 \\
2 & $7-15 \%$ & 3 \\
3 & $30-40 \%$ & 3 \\
4 & $100 \%$ & 1 \\
\hline
\end{tabular}

518 
519 Table 2. Fagus sylvatica leaf morphology parameters per light class, and significance of

520 differences between light classes $(\mathrm{P}<0.001 * * *, \mathrm{P}<0.01 * *, \mathrm{P}<0.05 *$, and $\mathrm{P}>0.05 \mathrm{Ns})$.

\begin{tabular}{|c|c|c|c|c|c|c|}
\hline \multirow{2}{*}{\multicolumn{2}{|c|}{ Parameters }} & \multicolumn{4}{|c|}{ Light class } & \multirow{2}{*}{$\mathbf{P}$} \\
\hline & & $1-5 \%$ & $7-15 \%$ & $30-40 \%$ & $100 \%$ & \\
\hline \multicolumn{2}{|l|}{ Leaf area $\mathbf{A}\left(\mathrm{mm}^{2}\right)$} & 1398 & 1412 & 1380 & 2258 & Ns \\
\hline \multicolumn{2}{|l|}{ Midrib length $\mathbf{L}(\mathrm{mm})$} & 55 & 54 & 55 & 65 & Ns \\
\hline \multicolumn{2}{|l|}{ Leaf width W (mm) } & 35 & 36 & 34 & 47 & Ns \\
\hline \multicolumn{2}{|l|}{ W/L } & 0.63 & 0.68 & 0.64 & 0.72 & $\mathrm{Ns}$ \\
\hline \multirow{3}{*}{ Midrib curvature $\mathbf{C}\left(\mathrm{mm}^{-1}\right)$} & mean & 0.01 & 0.02 & 0.02 & 0.02 & $\mathrm{Ns}$ \\
\hline & $\max$ & 0.05 & 0.06 & 0.06 & 0.06 & $\mathrm{Ns}$ \\
\hline & $\min$ & -0.01 & -0.01 & -0.02 & -0.02 & $\mathrm{Ns}$ \\
\hline \multirow{3}{*}{ Openess angle $O\left(^{\circ}\right)$} & mean & 164.0 & 165.9 & 163.6 & 148.5 & Ns \\
\hline & $\max$ & 174.7 & 176.8 & 176.8 & 174.3 & $\mathrm{Ns}$ \\
\hline & $\min$ & 150.2 & 150.2 & 146.3 & 113.3 & $* *$ \\
\hline \multirow{3}{*}{ Lamina twirl $\mathbf{T}\left(^{\circ}\right)$} & mean & 8.3 & 8.5 & 14.2 & 14.4 & $*$ \\
\hline & $\max$ & 18.0 & 17.9 & 35.3 & 41.5 & $*$ \\
\hline & $\min$ & 3.9 & 3.9 & 4.5 & 3.5 & $\mathrm{Ns}$ \\
\hline \multirow{3}{*}{ Allometric coefficient $K$} & $\mathbf{K}$ & 0.70 & 0.71 & 0.70 & 0.74 & $*$ \\
\hline & Kdist & 0.65 & 0.68 & 0.66 & 0.71 & Ns \\
\hline & Kprox & 0.74 & 0.75 & 0.76 & 0.74 & Ns \\
\hline \multirow{3}{*}{ Transversal curvature $\mathbf{T C}\left(^{\circ}\right)$} & mean & 170.1 & 174.3 & 170.0 & 167.5 & $\overline{\mathrm{Ns}}$ \\
\hline & $\max$ & 179.1 & 179.2 & 179.1 & 178.3 & $\mathrm{Ns}$ \\
\hline & $\min$ & 152.6 & 154.7 & 144.5 & 135.7 & $*$ \\
\hline \multirow{3}{*}{ Symmetry S } & mean & 0.49 & 0.52 & 0.50 & 0.52 & Ns \\
\hline & $\max$ & 0.55 & 0.59 & 0.55 & 0.55 & Ns \\
\hline & $\min$ & 0.42 & 0.44 & 0.41 & 0.42 & $\mathrm{Ns}$ \\
\hline
\end{tabular}




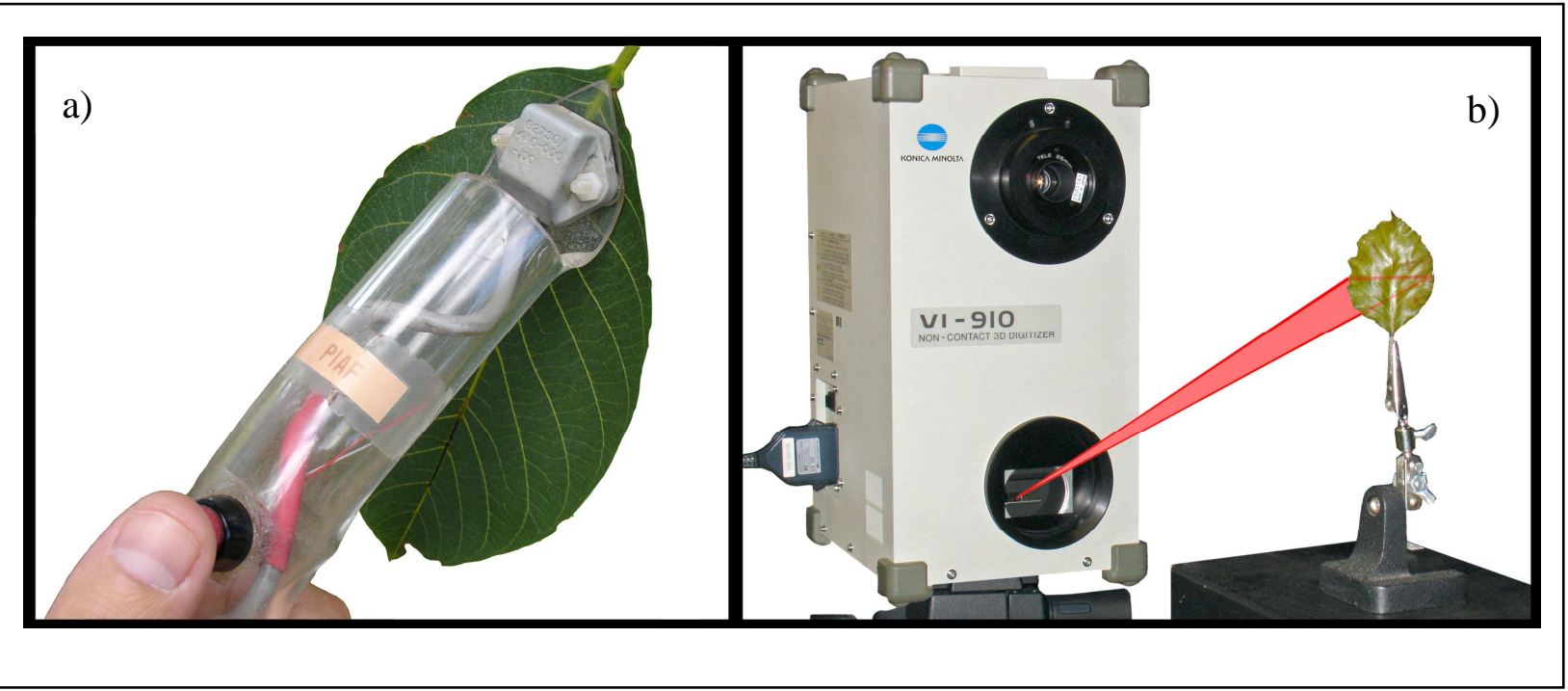

Fig. 1. Illustration of two digitizing methods: a) Leaf digitizing in a tree with a hand-held electromagnetic digitizer 3Space Fastrack Polhemus; the pointer is set parallel to the midrib

523 and the mean plane of the lamina and points the junction between petiole and lamina. b) Leaf

524 digitizing with a non-contact laser scan digitizer Konica Vi-910 on detached leaves. The light 525 red triangle mimics the emitted laser plane. 

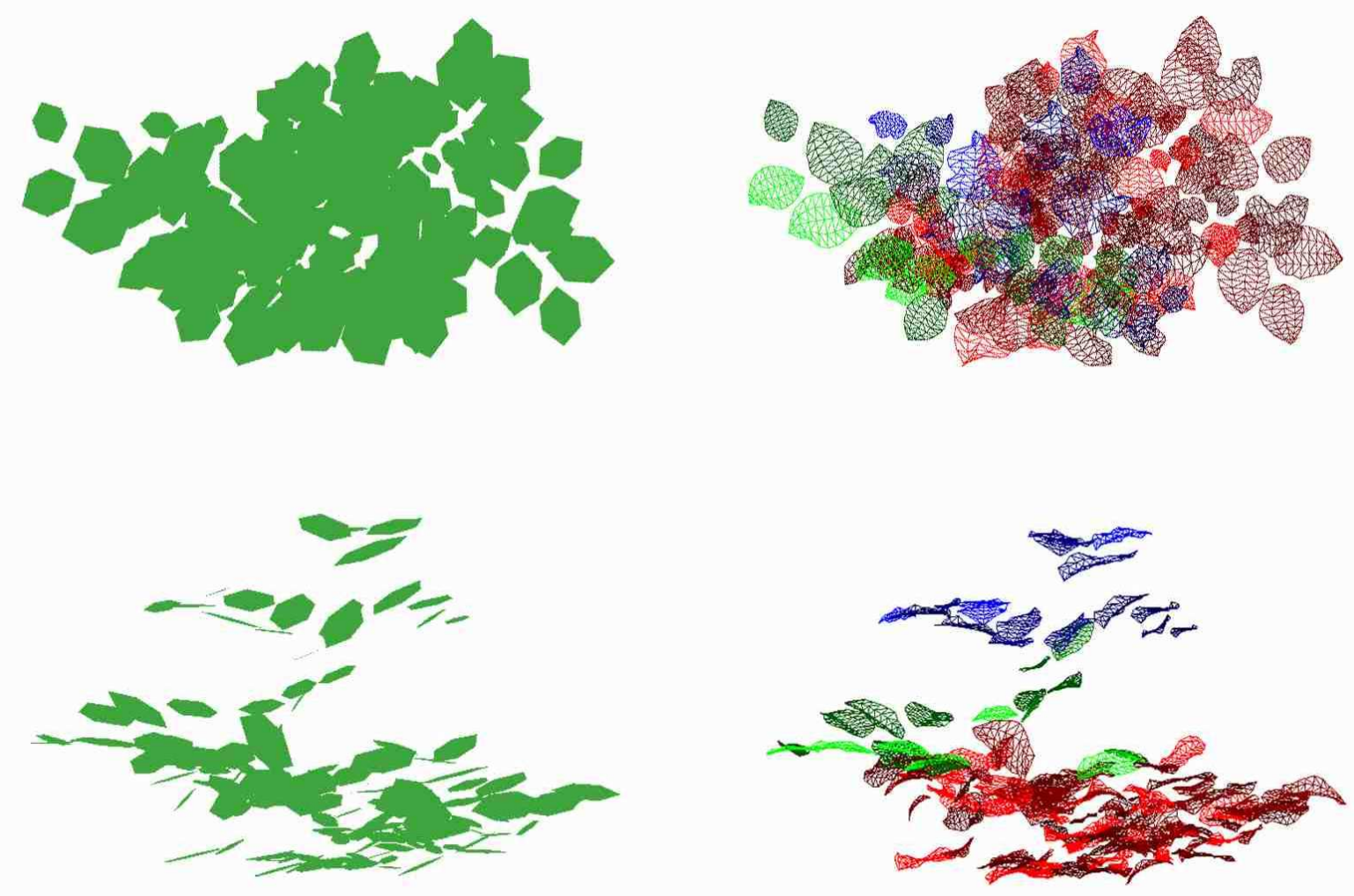

b)

528 Fig. 2. Images of three-dimensional plant mock-ups of the same tree (Fagus sylvatica) at 9\%

529 light viewed from the top (first line) or laterally (second line). a) Three-dimensional mock-up

530 made of planar hexagonal leaves. b) Three-dimensional mock-up made of non-planar

531 triangulated leaves. Blue, green and red false colours are assigned to non-planar leaves in top,

532 medium and bottom canopy layers. 


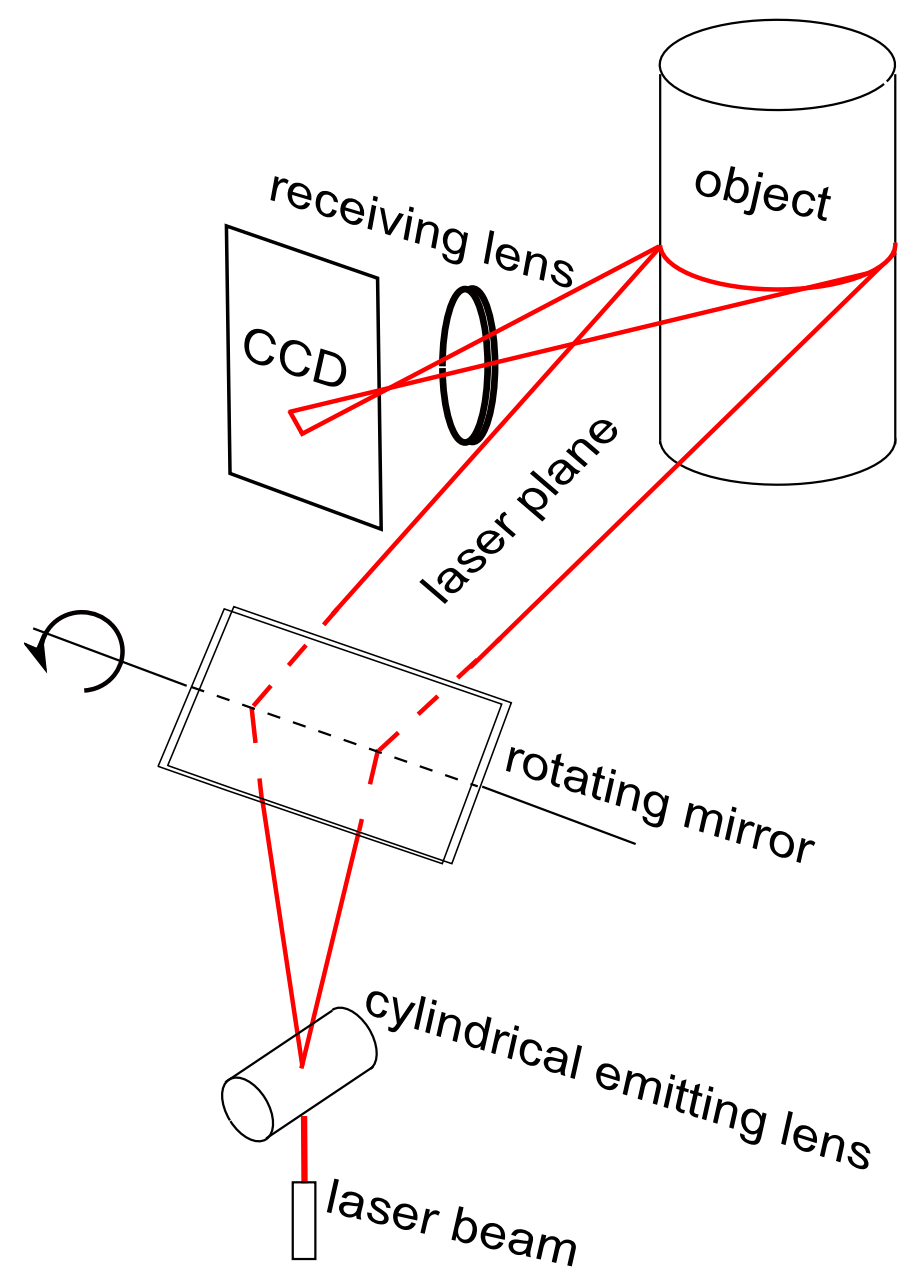

535 Fig. 3. Illustration of the light stripe method used in the Konica Vi-910 scanner: a red laser

536 beam is emitted through a cylindrical lens in order to generate a laser plane. The laser plane is

537 sent to a rotating mirror in order to scan the object. Reflected light by the object is converted 538 into distance information by using an active triangulation principle. The conversion is

539 achieved through a charge-coupled device camera. 


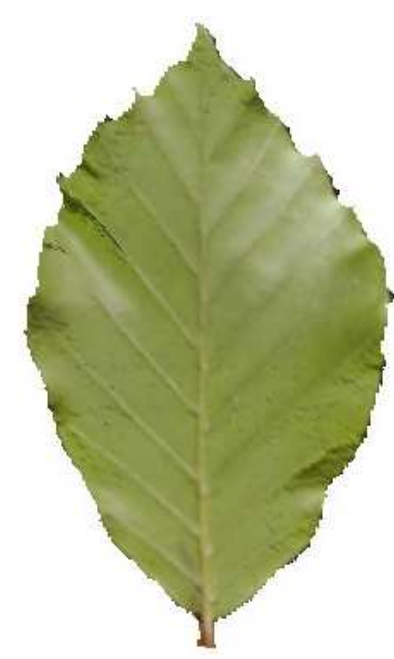

a)

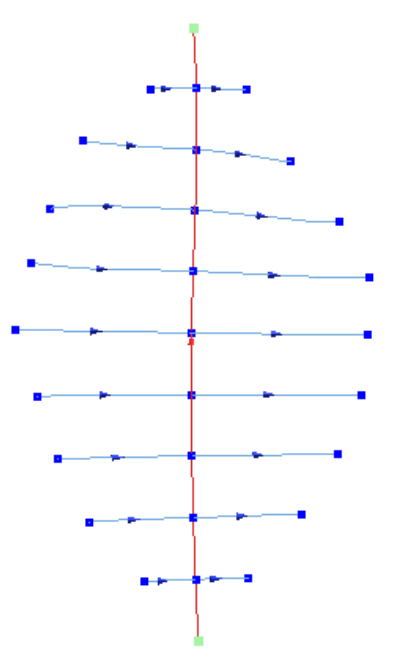

b)

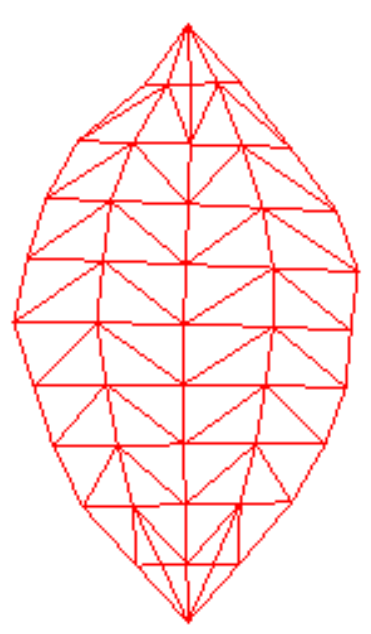

c)

542 Fig. 4. Processing of the three-dimensional leaf point cloud acquired with a non-contact laser

543 scan digitizer (Konica Vi-910) to extract morphological parameters and obtain a non-planar

544 leaf model made of 72 triangles: a) Scanned Fagus sylvatica leaf made of 18927 coloured

545 points; b) Nine slicing NURBS (Non Uniform Rational B-Spline) curves devoted to the 546 extraction of leaf morphological parameters and the construction of a triangulated leaf model;

547 c) Resulting triangulated leaf model composed of 72 triangles. 


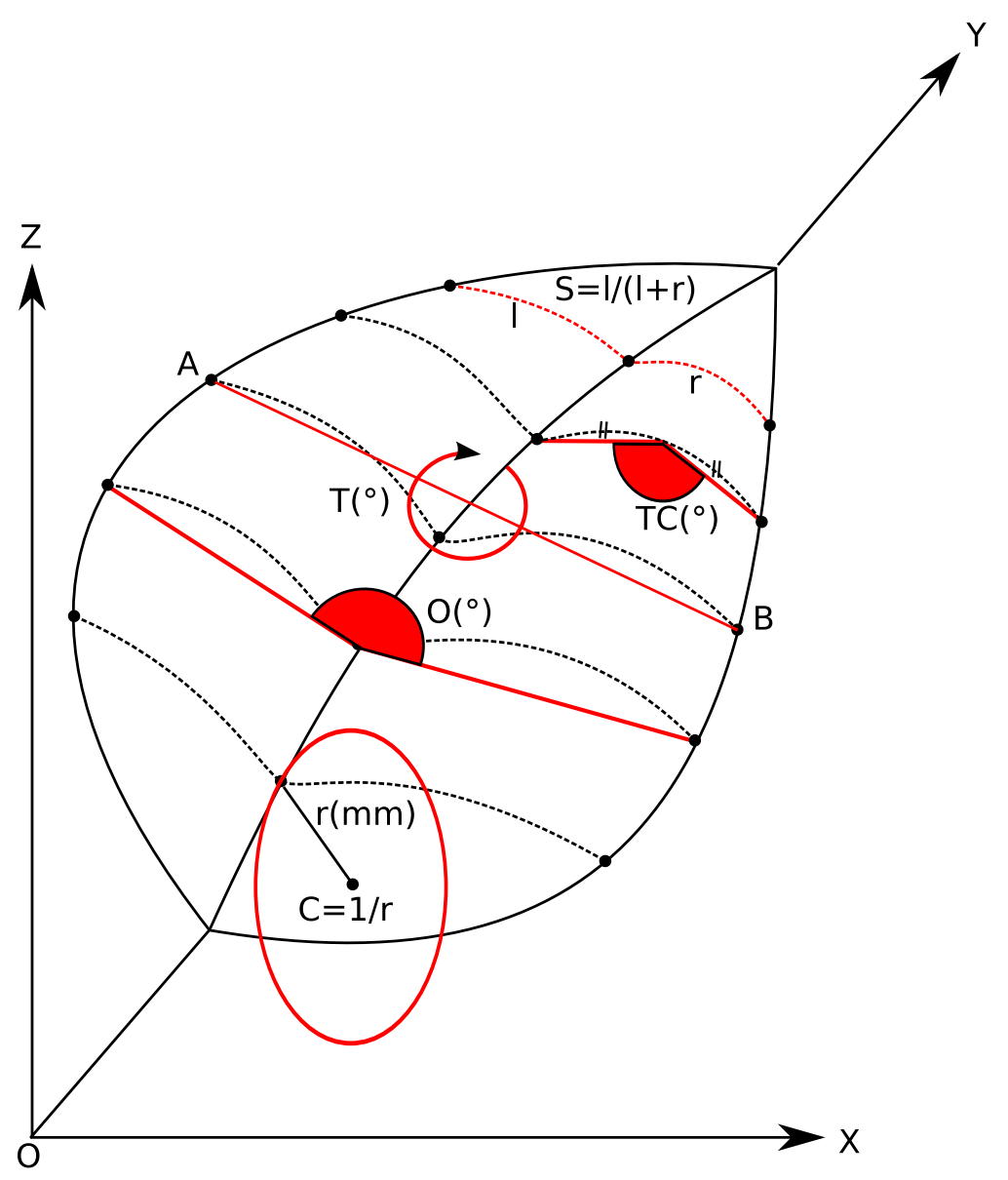

550 Fig. 5. Illustration of five morphological parameters of a Fagus sylvatica leaf, namely midrib

551 curvature $\mathrm{C}$, openness angle between two-half laminas $\mathrm{O}$, lamina twirl $\mathrm{T}$, transversal 552 curvature angle of lamina TC and symmetry between the two half-laminas S. First slicing 553 curve, illustration of $\mathrm{C}\left(\mathrm{mm}^{-1}\right)$ i.e. the inverse of the osculating circle radius; second slicing 554 curve, $\mathrm{O}\left({ }^{\circ}\right)$; third slicing curve, $\mathrm{T}\left({ }^{\circ}\right)$, defined as the rotation angle of the segment $\mathrm{AB}$ around 555 the Y axe; fourth slicing curve, TC $\left(^{\circ}\right)$; fifth slicing curve, $\mathrm{S}$. 


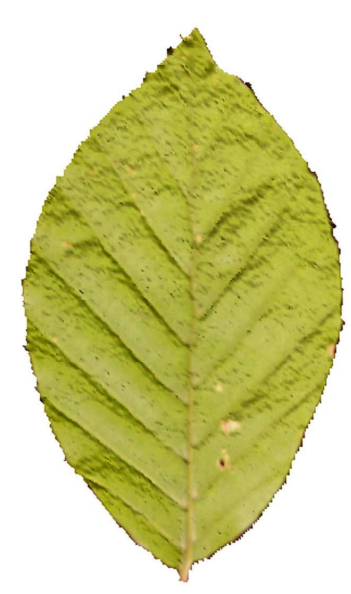

Light $1 \%$

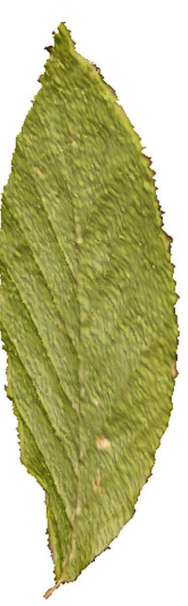

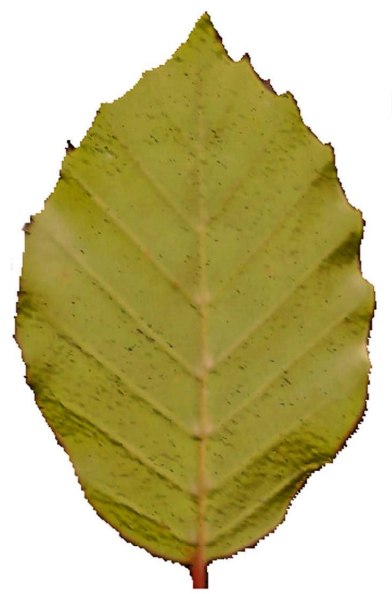

Light 15\%

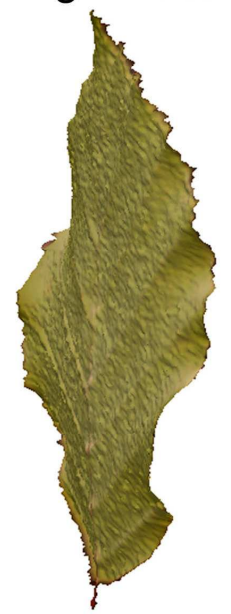

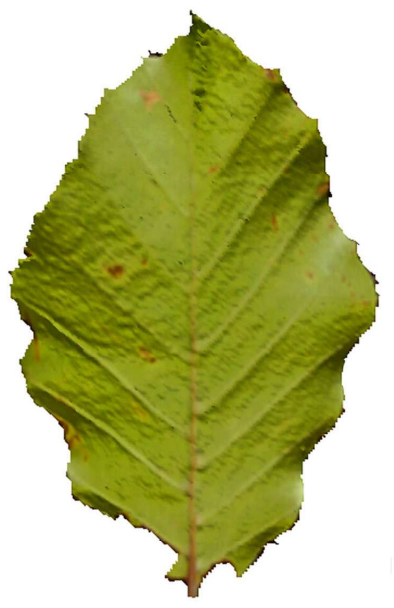

Light 37\%

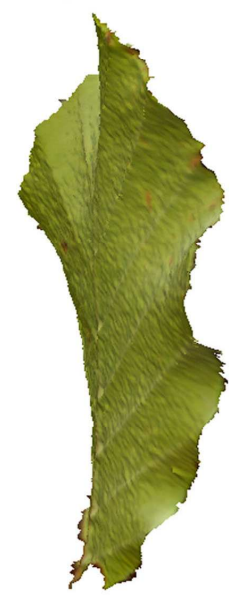

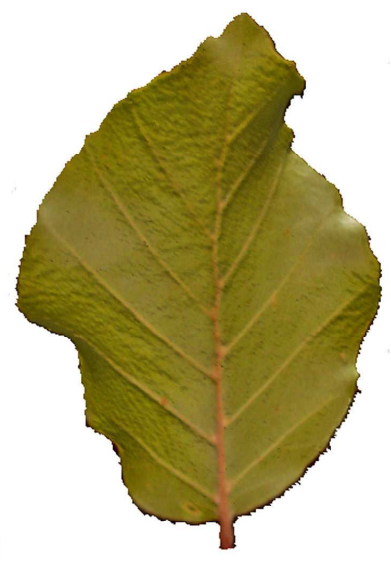

Light 100\%

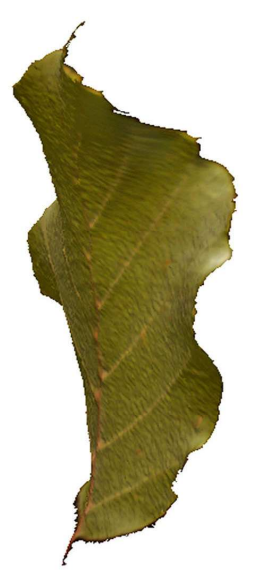

560 Fig. 6. Fagus sylvatica leaves as a point cloud originated from the laser scanner (Konica Vi-

561 910) for some young trees sampled under different light availabilities. Top panel:

562 perpendicular view to the main leaf plane. Bottom panel: parallel view to the main leaf plane 


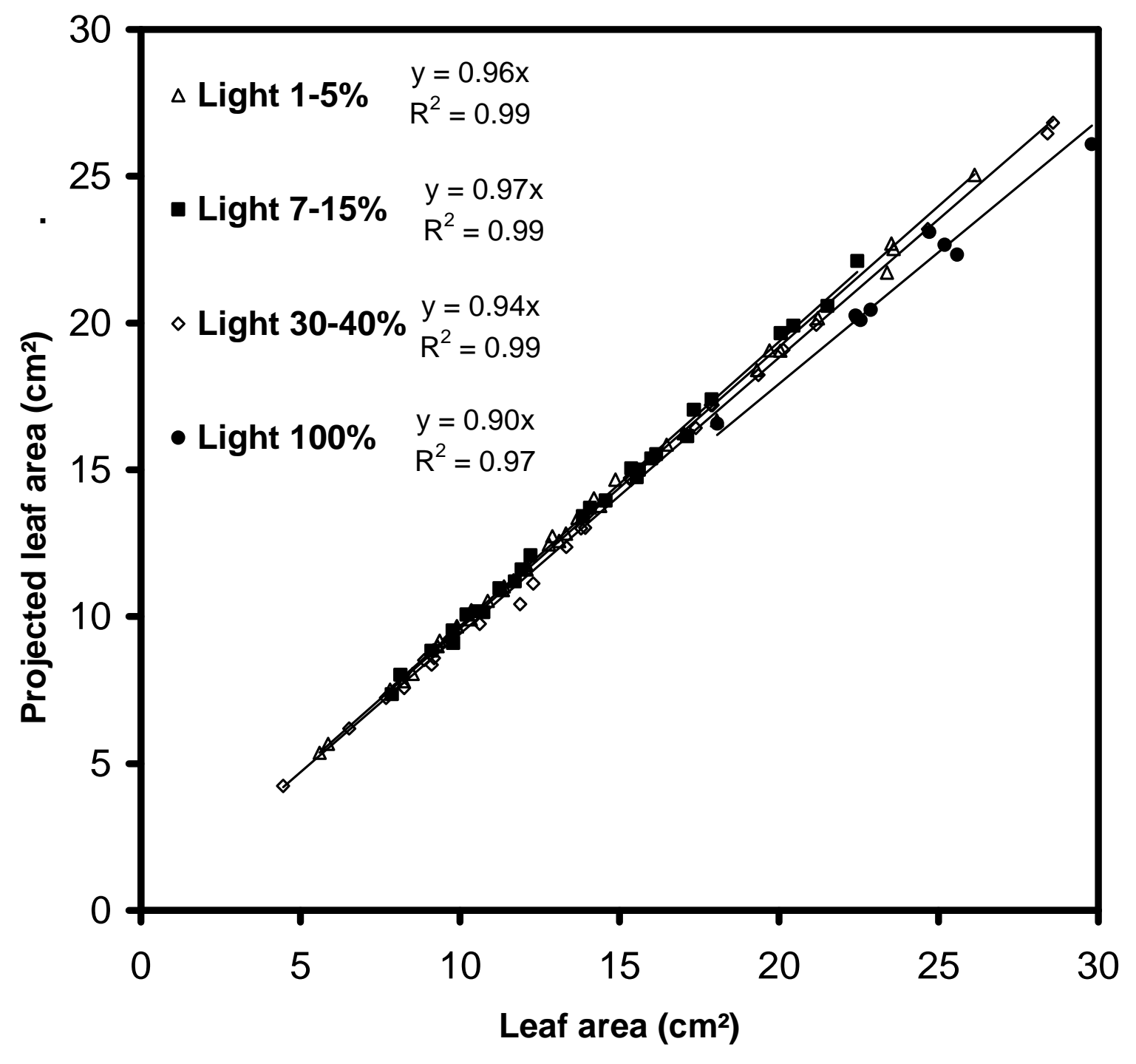

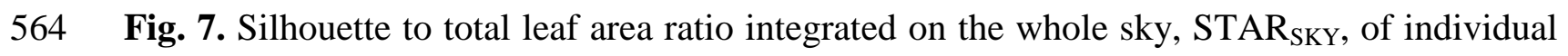
565 non-planar leaves of Fagus sylvatica in central France under different light availabilities, 566 shown as a scatter plot between individual leaf area and projected leaf area averaged over all 567 sky directions. 


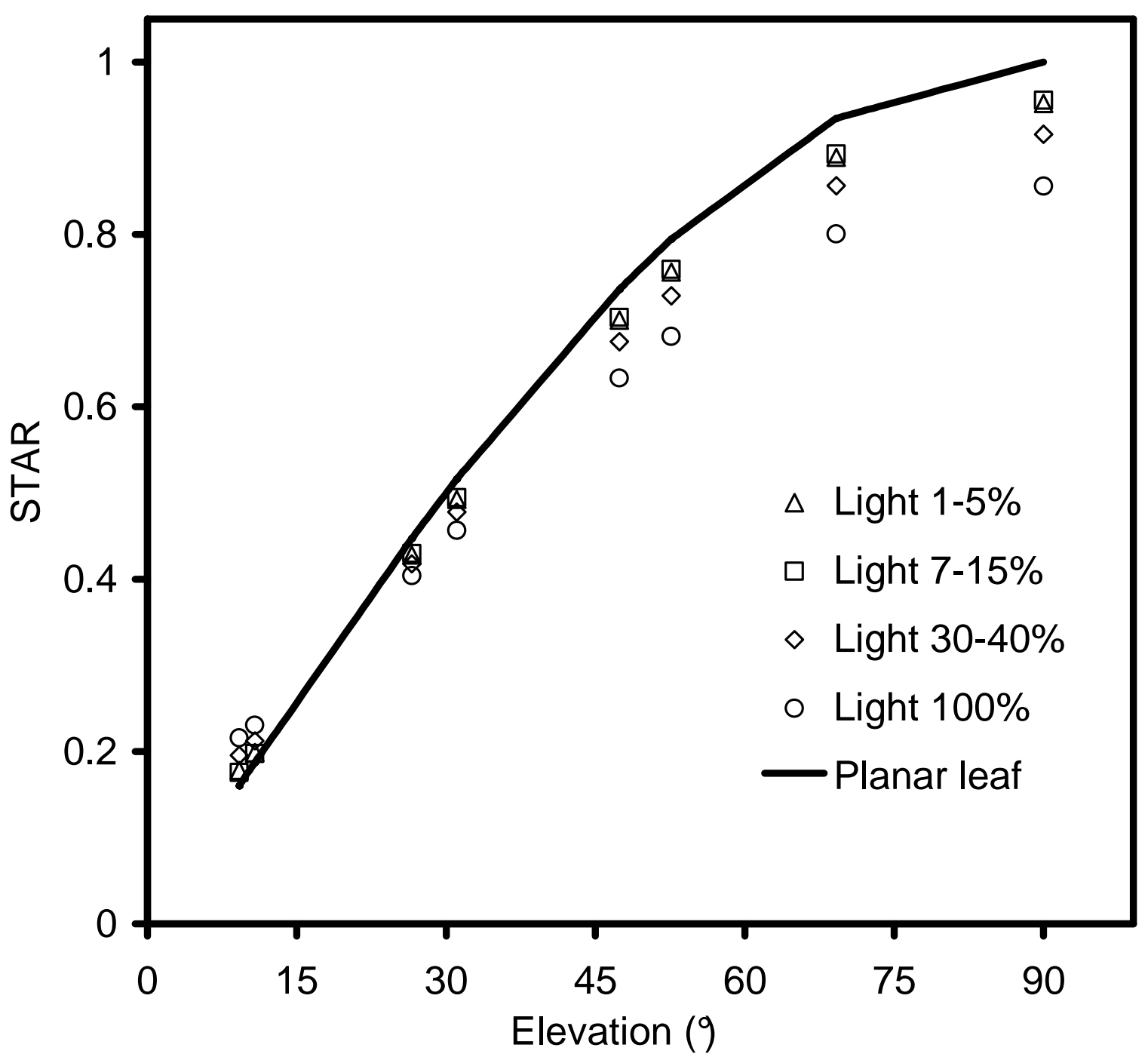

569 Fig. 8. Directional STAR (Silhouette to Total leaf Area ratio) as a function of elevation angle 570 of individual non-planar leaves of Fagus sylvatica under different light availabilities in 571 Central France and in comparison with planar leaves (dark line). 


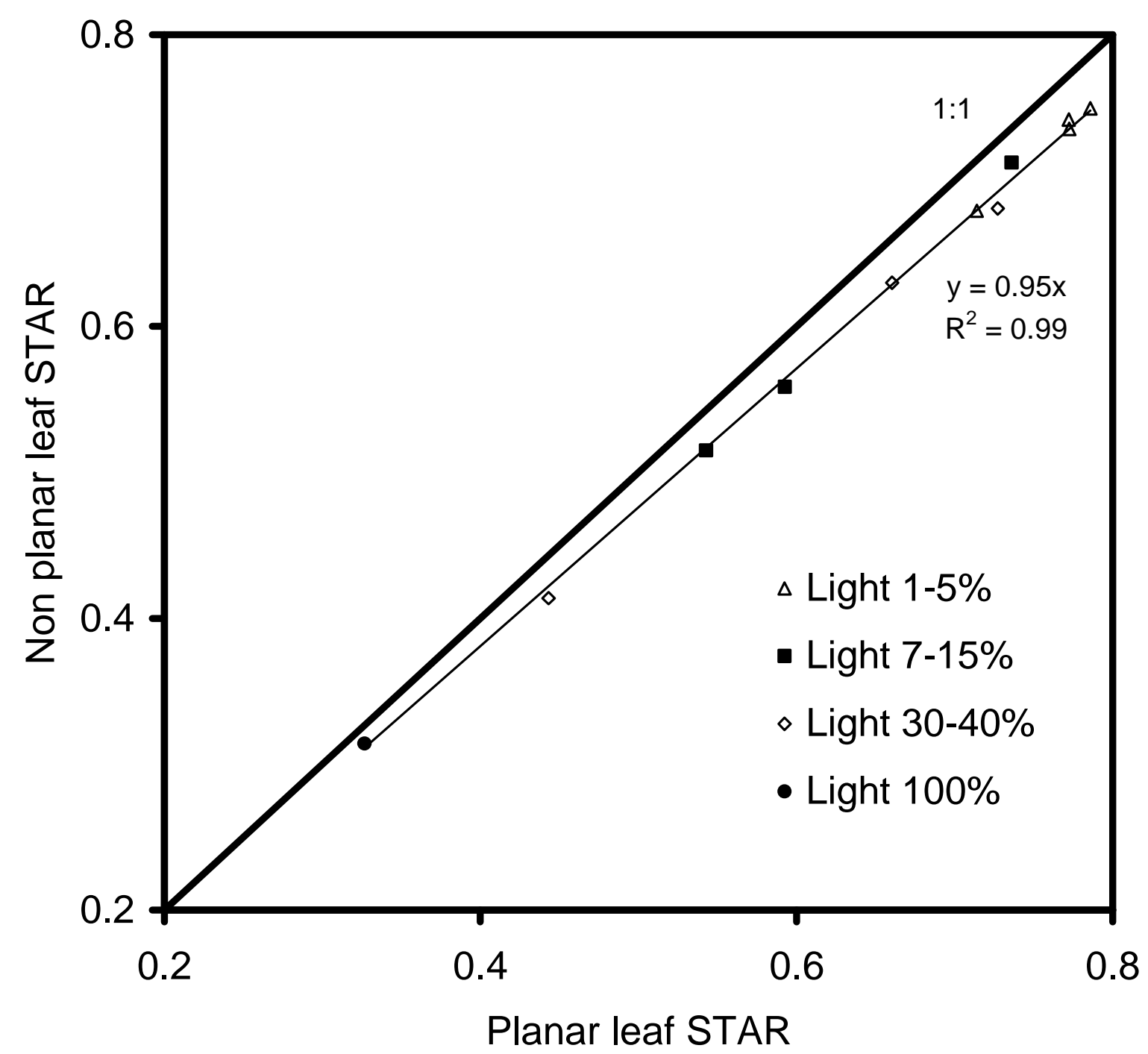

574 Fig. 9. Comparison between silhouette to total leaf area ratio integrated on the whole sky

575 (STAR $\left._{\mathrm{SKY}}\right)$ of Fagus Sylvatica trees under different light availabilities in central France 576 calculated on mock-ups with planar and non-planar leaves. 


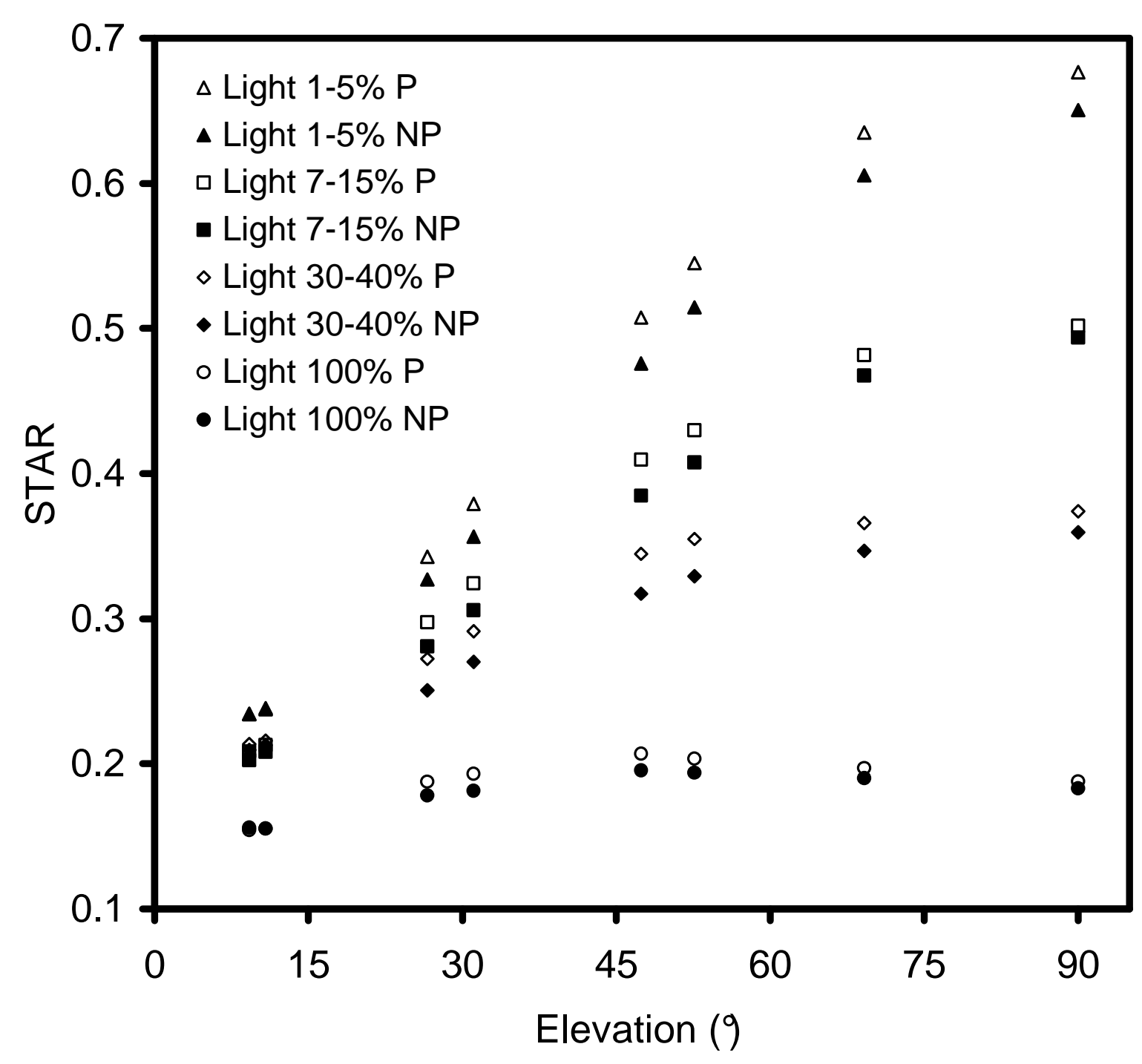

579 Fig. 10. Directional silhouette to total leaf area ration (STAR) as a function of elevation angle

580 of Fagus Sylvatica trees under different light availabilities in central France calculated on 581 mock-ups with planar (P) and non-planar (NP) leaves. 